\title{
Karyotype Variability in Regenerated Plants of Urgineo indica Kunth.
}

\author{
Sumita Jha and Sumitra Sen \\ Centre of Advanced Study (Cell and Chromosome Research), \\ Department of Botany, University of Calcutta, \\ Calcutta-700 019, India
}

Accepted June 16, 1986

Tissue culture and subsequent plant regeneration has now been developed for several species and the nature of genetic and chromosomal aberrations in regenerated plants have been demonstrated (Reisch 1983). In addition to gross changes in chromosome numbers, more cryptic chromosome rearrangements may be responsible for genetic variation in cultured cells and regenerated plants (Larkin and Scowcroft 1981). Chromosome breakage and reunion, multicentrics and translocations have been observed in the plants derived from cultures of barley (Orton 1980). Cummings et al. (1976) and McCoy et al. (1982) observed heteromorphic pairs (deletions or translocations) in oat somaclones. Heteromorphic pairs were also found in maize somaclones (Green et al., 1977). Cytogenetic changes have also been observed in regenerated plants of Alfa alfa (McCoy and Bingham 1977), Celery (Bowers and Orton 1982), Lycopersicum (Ancora and Sree Ramlulu 1981), wheat (Bennici and D'Amato 1978), potato (Sree Ramlulu et al. 1983) and Brassica napus (Newell et al. 1984).

In Liliaceae, although protocols for plant regeneration are available for over 26 species (Flick et al. 1983) data on cytogenetic analysis are rather meagre (Novak 1980, Krikorian et al. 1981 and Sheridan 1975). In the present project on tissue culture of medicinally important plants of family Liliaceae, a large number of plants were regenerated from bulb derived calli of Urginea indica (Jha et al. 1984). This plant is of special significance for bufadienolide content (Jha and Sen 1981, 1983a). The present investigation is aimed to examine the chromosomal variations, if any, occurring in callus regenerated plants.

\section{Materials and method}

Regeneration from tissue culture: A high yielding diploid $(2 n=20)$ cytotype of $U$. indica (Jha and Sen 1983b) was used in this study. Plants were regenerated from callus tissues derived from bulb explants following methods published earlier (Jha et al. 1984). Calli were induced on bulb explants on a modified basal medium of Murashige and Skoog (1962) supplemented with 2,4-D $4 \mathrm{mgl}^{-1}+\mathrm{NAA}_{2} \mathrm{mgl}^{-1}+$ Kinetin $2 \mathrm{mgl}^{-1}+$ yeast extract $1 \mathrm{gl}^{-1}$. Shoot primordia (20-30/explant) developed after 2-3 subcultures in that medium. Subsequent subculturing in 2,4-D free medium led to increased growth of shoot buds which developed to bulbous plantlets. Clusters of 4-8 plantlets were transferred to basal medium containing NAA $\left(0.1 \mathrm{mgl}^{-1}\right)+\mathrm{Kn}$ $\left(0.5 \mathrm{mgl}^{-1}\right)$ to give rooted plants after 20-24 weeks. Individual plants were removed to MS liquid medium devoid of growth regulators prior to transfer to potted soil (Jha et al. 1984). Plantlets were transplanted to individual pots. Survival from aseptic conditions to the field was $90 \%$ and although plants were vigorous by the end of the first growing season but the flowering was absent.

Chromosome procedures: Root-tips were used to study mitotic metaphases. Bulbs, after one year of transfer to potted soil, were denuded and allowed to root. Root of 1-2 cm length were regularly collected, pretreated in $0.05 \%$ colchicine and saturated solution of PDB (1:1) 
for 2-3 hours and fixed in acetic ethanol for overnight. Root tips were stained in aceto-orcein and feulgen. Individual bulbs from which roots has been severed were allowed to generate new roots and these in turn were also examined several times in succession. Hence, a large population of cells from roots of callus regenerated plants were sampled. Five cells with well

Table 1. Chromosome number of plants regenerated from callus derived from bulb scale explants in $U$. indica (based on 5 root tips/plant for mitotic determinations)

\begin{tabular}{ccc}
\hline \multirow{2}{*}{ Chromosome number } & \multicolumn{2}{c}{ Regenerated plants } \\
\cline { 2 - 3 } & number & $\%$ \\
\hline 20 & 97 & 81 \\
40 & 17 & 14 \\
41 & 1 & 1 \\
$20,28,30,40$ & 5 & 4 \\
\hline
\end{tabular}

Table 2. Frequency of karyotype alterations in regenerated plants of $U$. indica

\begin{tabular}{|c|c|c|c|c|c|c|}
\hline \multirow{3}{*}{$\begin{array}{l}\text { Total no. of } \\
\text { plants analyzed }\end{array}$} & \multicolumn{2}{|c|}{ No. of plants showing } & \multirow{2}{*}{\multicolumn{4}{|c|}{$\begin{array}{c}\text { No. of plants out of } 36 \\
\text { showing alteration in } \\
\text { chromosome types }\end{array}$}} \\
\hline & \multirow{2}{*}{$\begin{array}{l}\text { unaltered } \\
\text { karyotype }\end{array}$} & \multirow{2}{*}{$\begin{array}{c}\text { altered } \\
\text { karyotype }\end{array}$} & & & & \\
\hline & & & A & B & D & $A$ and $D$ \\
\hline Diploid 70 & 41 & 29 & 2 & 0 & 2 & 25 \\
\hline Tetraploid 12 & 5 & 7 & 0 & 0 & 1 & 6 \\
\hline Total 82 & $46(56 \%)$ & $36(44 \%)$ & 2 & 0 & 3 & 31 \\
\hline
\end{tabular}

Table 3. Occurrence of different chromosome types (altered and unaltered) in regenerated diploid and tetraploid plants of $U$. indica

\begin{tabular}{|c|c|c|c|c|}
\hline \multicolumn{2}{|c|}{ No. of regenerated plants } & \multirow{2}{*}{$\begin{array}{c}\begin{array}{c}\text { Chromosome } \\
\text { number }\end{array} \\
20 \\
\end{array}$} & \multirow{2}{*}{$\begin{array}{l}\text { Karyotype formula } \\
A_{8(2)} B_{1(2)} D_{1(2)} \\
\end{array}$} & \multirow[t]{2}{*}{ Figs. } \\
\hline Control (in vitro) & - & & & \\
\hline \multirow{2}{*}{$\begin{array}{l}\text { Plants with stable } \\
\text { karyotype }\end{array}$} & 41 & 20 & $\begin{array}{lll}A_{8(2)} & B_{1(2)} & D_{1(2)}\end{array}$ & $7,7 \mathrm{a}, 11,11 \mathrm{a}, 16 \mathrm{~h}$ \\
\hline & 5 & 40 & $A_{5(4)+1(2)} B_{1(4)} D_{1(2)}$ & - \\
\hline \multirow{12}{*}{$\begin{array}{l}\text { Plants showing } \\
\text { alteration in } \\
\text { karyotype }\end{array}$} & 4 & 20 & $\mathbf{A}_{7(2)+1+1} \mathbf{B}_{1(2)} \mathrm{D}_{1}^{\prime} \mathbf{D}_{1}^{\prime \prime}$ & $3,3 a, 16 b$ \\
\hline & 6 & 20 & $A_{9(2)} B_{1(2)} D_{1} D_{1}^{\prime}$ & $4,4 a, 16 a$ \\
\hline & 7 & 20 & $A_{7(2)+1+1} B_{1(2)} D_{1} D_{1}^{\prime}$ & $5,5 a$ \\
\hline & 2 & 20 & $\mathbf{A}_{7(2)+1} \mathbf{A}_{1}^{\prime} \mathbf{B}_{1(2)} \mathrm{D}_{1(2)}$ & $6,6 a, 16 d$ \\
\hline & 1 & 20 & $A_{7(2)+1} B_{1(2)} C_{1}^{\prime} D_{1} D_{1}^{\prime \prime}$ & $8,8 \mathrm{a}, 16 \mathrm{c}$ \\
\hline & 2 & 20 & $A_{7(2)+1+1} B_{1(2)} D_{1} D_{1}^{\prime}$ & $9,9 a$ \\
\hline & 5 & 20 & $A_{7(2)+1+1} B_{1(2)} D_{1} D_{1}^{\prime}$ & $10,10 a, 16 f$ \\
\hline & 1 & 20 & $A_{8(2)} \mathbf{B}_{1(2)} \mathbf{D}_{1}^{\prime \prime}{ }_{(2)}$ & $12,12 a, 16 e$ \\
\hline & 1 & 20 & $A_{7(2)+1} B_{1(2)} C_{1} D_{1} D_{1}^{\prime}$ & $13,13 a$ \\
\hline & 1 & 40 & $A_{8(4)+1(2)} B_{1(4)} D_{1} D_{1}^{\prime}$ & $14 \mathrm{c}, 14 \mathrm{a}, 14 \mathrm{~b}$ \\
\hline & 6 & 40 & $\mathrm{~A}_{3(4)+1+1} \mathrm{~B}_{1(4)} \mathrm{D}_{1} \mathrm{D}_{1}^{\prime \prime}$ & - \\
\hline & 1 & 41 & $\mathbf{A}_{8(1)+4(2)+1+1} \mathbf{B}_{1(4)} \mathbf{D}_{1(3)}$ & $15 \mathrm{c}, 15 \mathrm{a}, 15 \mathrm{~b}$ \\
\hline
\end{tabular}

Plate 1. Figs. 1-13, 1, types of chromosomes present in in vitro regenerated plants of $U$. indica. Altered chromosome types are represented in black. 2 , somatic metaphase plate $(2 n=20)$ of source plant from the field. Arrow indicate chromosomes with secondary constrictions. 3-13, structural alterations in nucleolar and non-nucleolar chromosomes in ten diploid regenerated plants of $U$. indica. Altered chromosome types are represented in black. 3, 12, showing alteration in both type of D chromosomes. $4,5,8,9,10,13$, showing alteration in one type D chromosome. 6 , showing altered $\mathrm{A}^{\prime}$ type chromosome. 7, 11, showing a pair of normal $\mathrm{D}$ type chromosome. 8 , showing altered $\mathrm{C}^{\prime}$ type chromosome, 13, showing altered $\mathrm{C}$ type chromosome. 


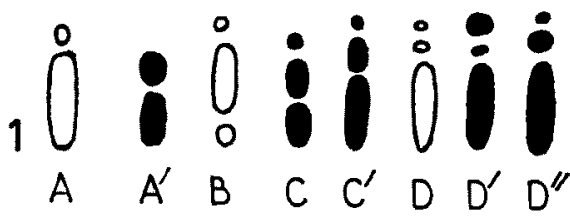
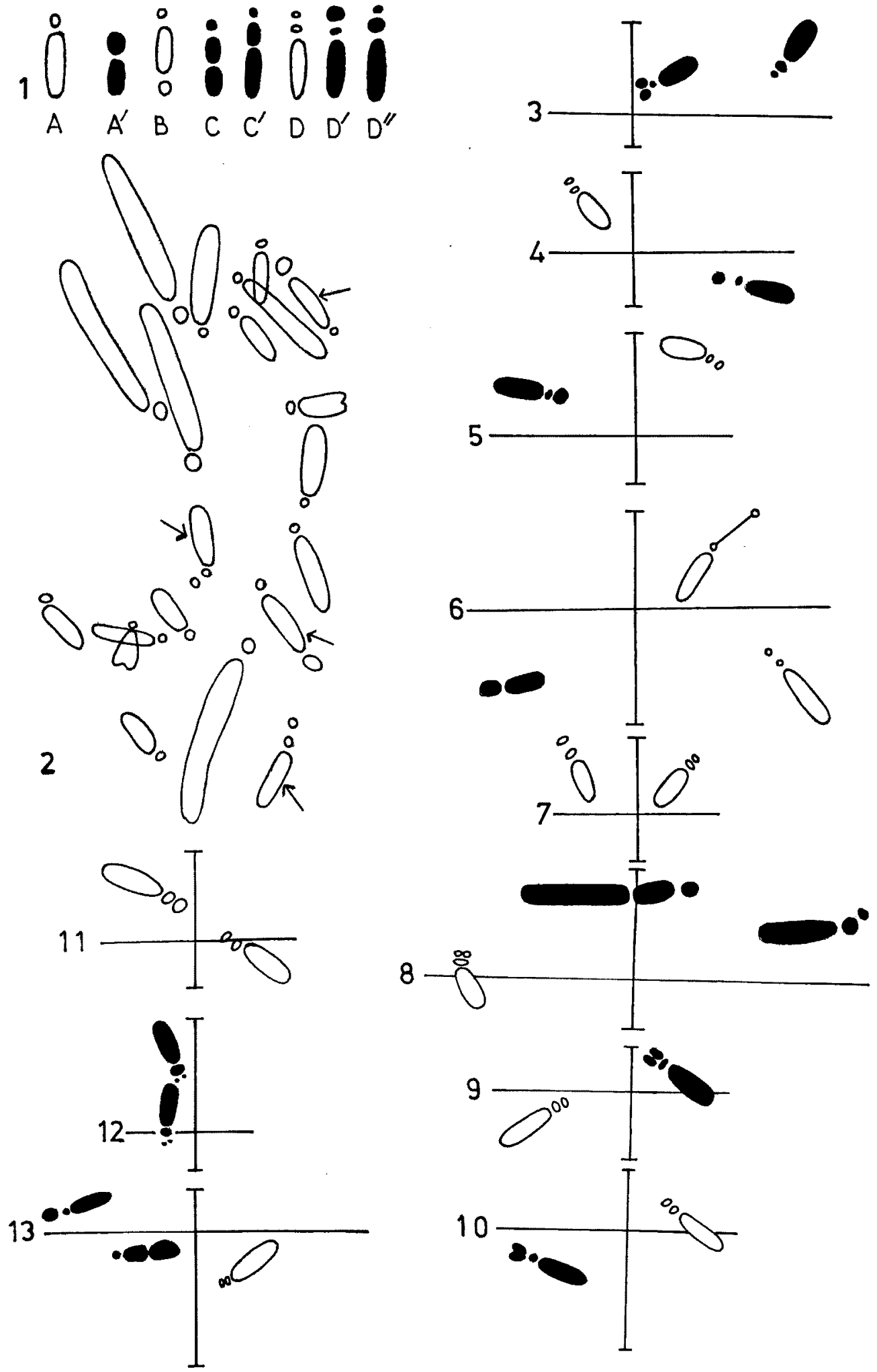

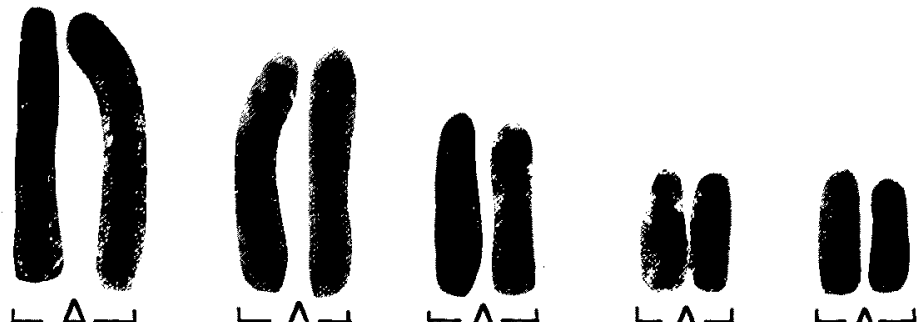

는

ᄂA-
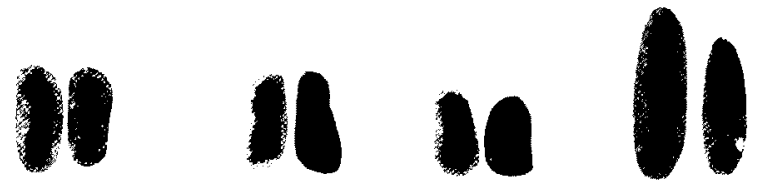

LA-

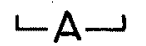

$\leftarrow A-$

느-

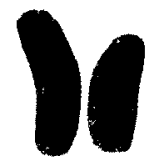

ᄂD-
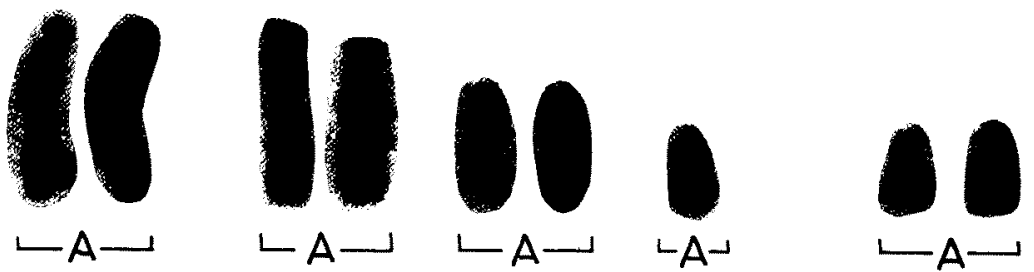

ᄂA
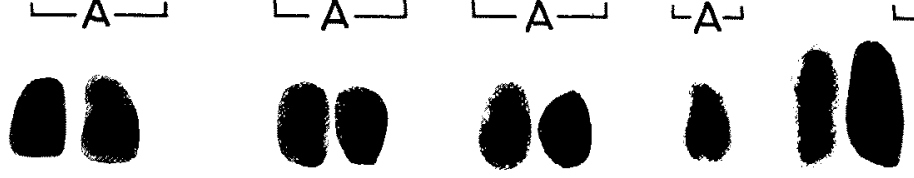

ᄂA-

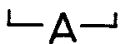

ᄂA-

${ }^{-} A^{-}$

$\leftarrow B-$

'D'

$3 a$
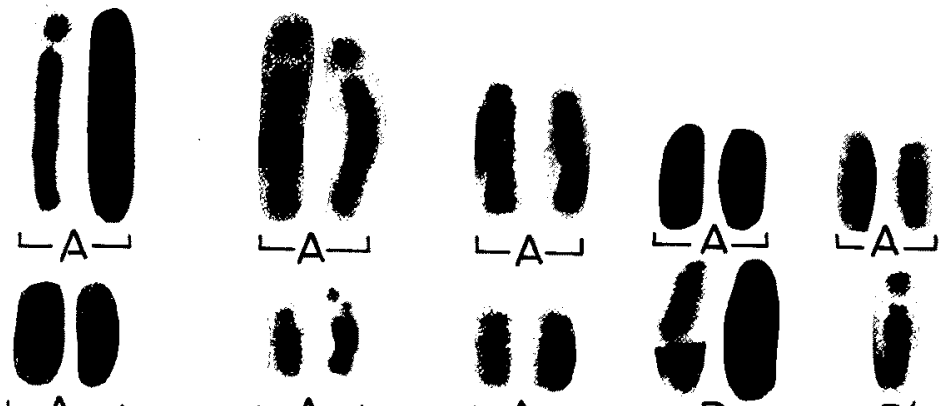

$4 a$
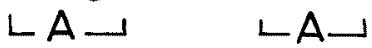

LA

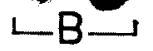

$\llcorner$ L' ᄂD」
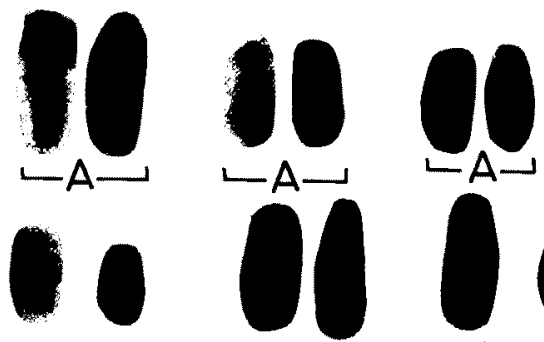

$-A-$
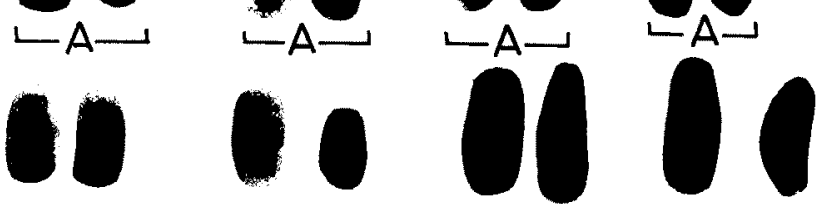

ᄂA-
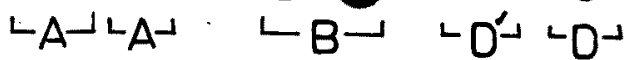

$5 a$

Figs. 2a-5a. 2a, idiogram (corresponding to Fig. 2) of a diploid source plant. $3 \mathrm{a}=\mathrm{Sa}$, idiogram (corresponding to karyotypes represented in Figs. 3-5 of diploid regenerated plants. 
(1) I I ㄴ.11) UIIN 00010 IIII II ou II a 40 (1) ) II liso an a. a in w llo. 

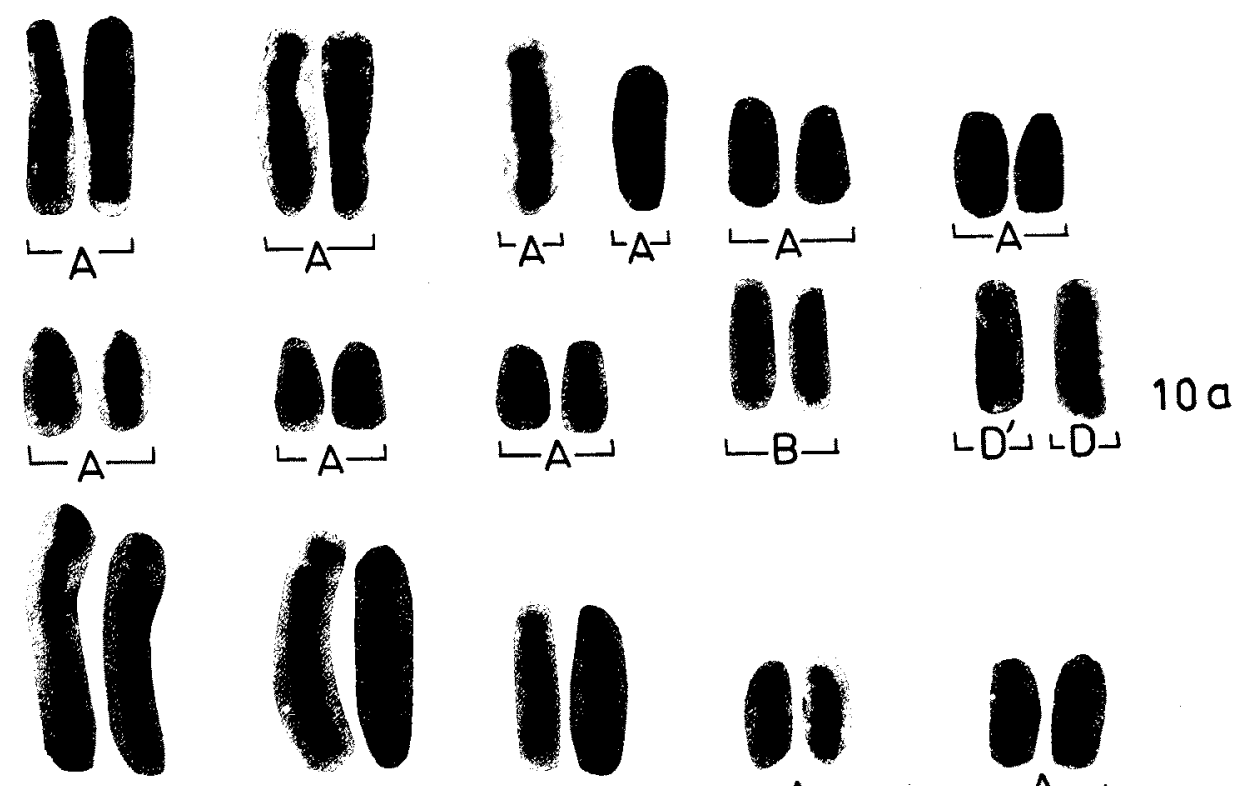

$\llcorner A \longrightarrow$
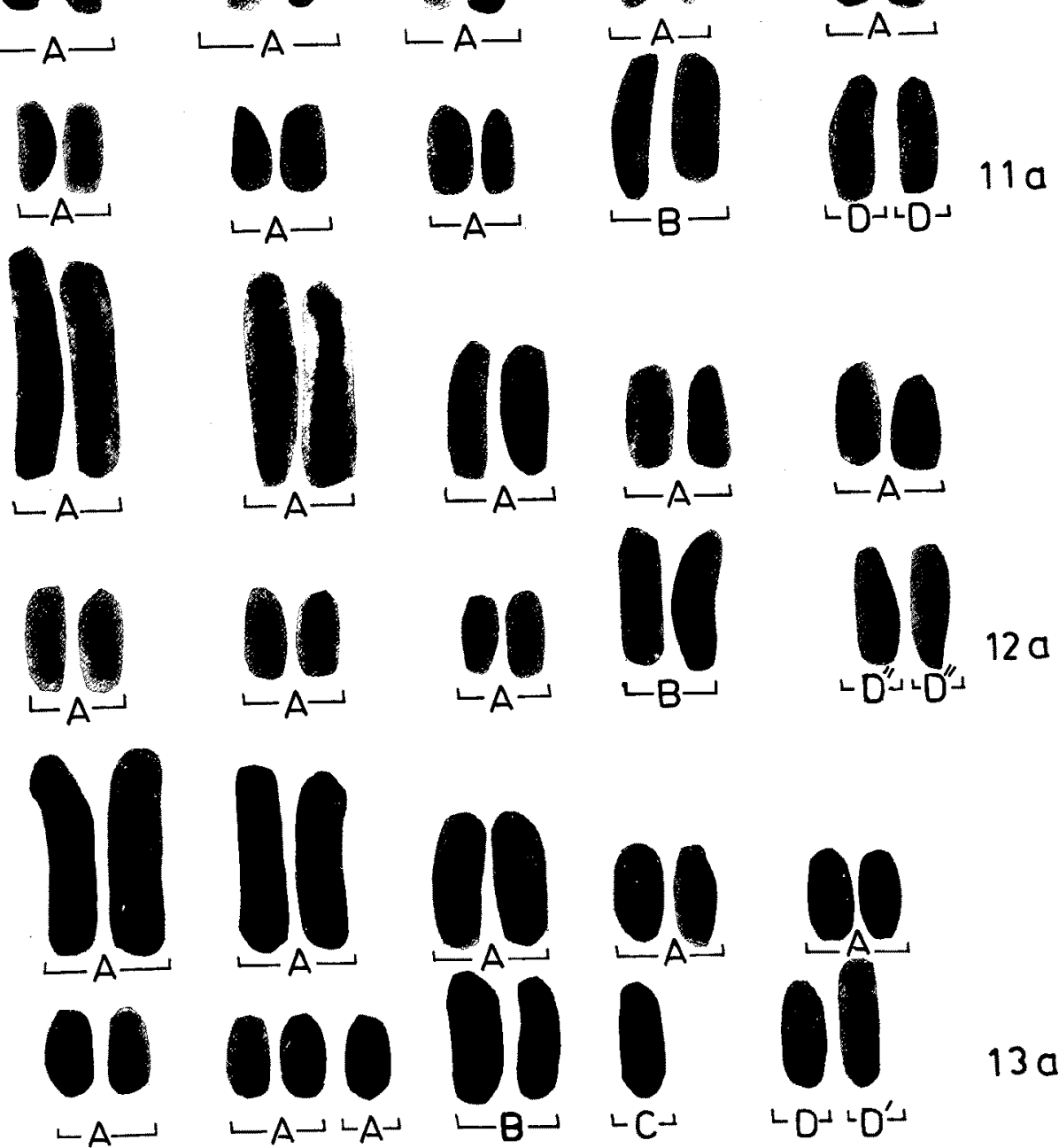

130

10a-13a, Idiograms (corresponding to karyotypes represented in Figs. 10-13) of diploid regenerated plants. 
spread chromosomes from each bulb were randomly selected for comparison between plants. Long arm, short arm, centromeric index measurements were used to construct idiogram for each plant. In all, chromosome numbers of 120 plants were determined and karyotype analysis of 82 randomly selected plants were done.

\section{Results}

A comparison of plants derived from culture in terms of bulb size and leaf (length and breadth) revealed no difference between cultured and non-cultured plants. There were no gross morphological features that enable distinction between the two groups of plants. Attention was, therefore, focussed to chromosome number and morphology.
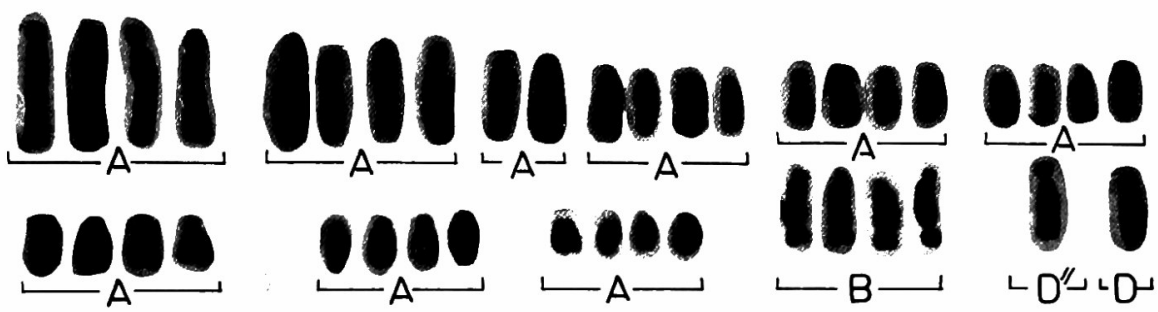

140
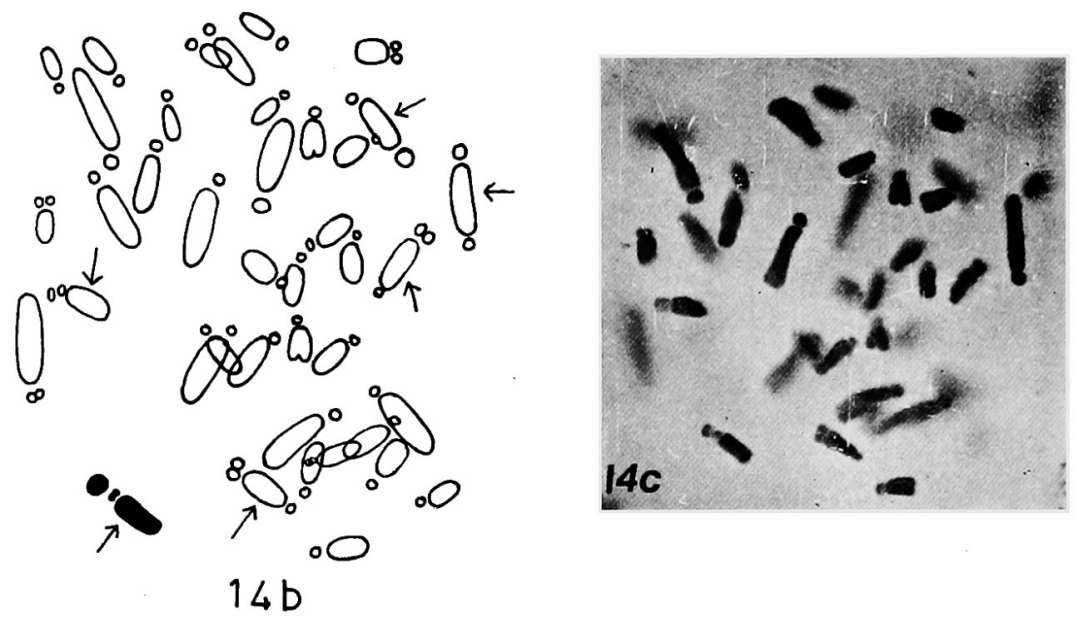

Fig. 14a, idiogram of a tetraploid regenerated plant corresponding to $14 b$ and $14 c$. 14b, 14c, somatic metaphase plates from tetraploid regenerated plant showing 40 chromosomes. Arrow indicate chromosome with secondary constrictions. Altered chromosome is represented in black,

Each explant in culture produced $>20$ plants of which $12-15$ could be reared to maturity and transferred to soil. Plants were selected at random and analyzed.

Chromosome number of regenerated plants: A total of 120 plants derived from callus cultures were analyzed. Plants regenerating only from younger cultures (12-14) week old were analyzed, as in older calli, shoot regeneration was completely suppressed. Hence, the variation in chromosome numbers obtained is independent of callus age as all the plants were derived from calli of nearly same age.

Of the 120 plants, $81 \%$ exhibited the expected chromosome number for $U$. indica $(2 n=20)$, $14 \%$ were tetraploid and $4 \%$ were unresolved mixoploids (Table 1). One plant was found to 
be a hypertetraploid (41 chromosomes). The extra small chromosome was present in 31 out of 45 metaphase plates counted. The plant produced a number of daughter bulbs in soil.

The mixoploids showed a variation in chromosome number ranging from diploid and tetraploid metaphases to triploid and hyperdiploid numbers. However, $40-60 \%$ of metaphases
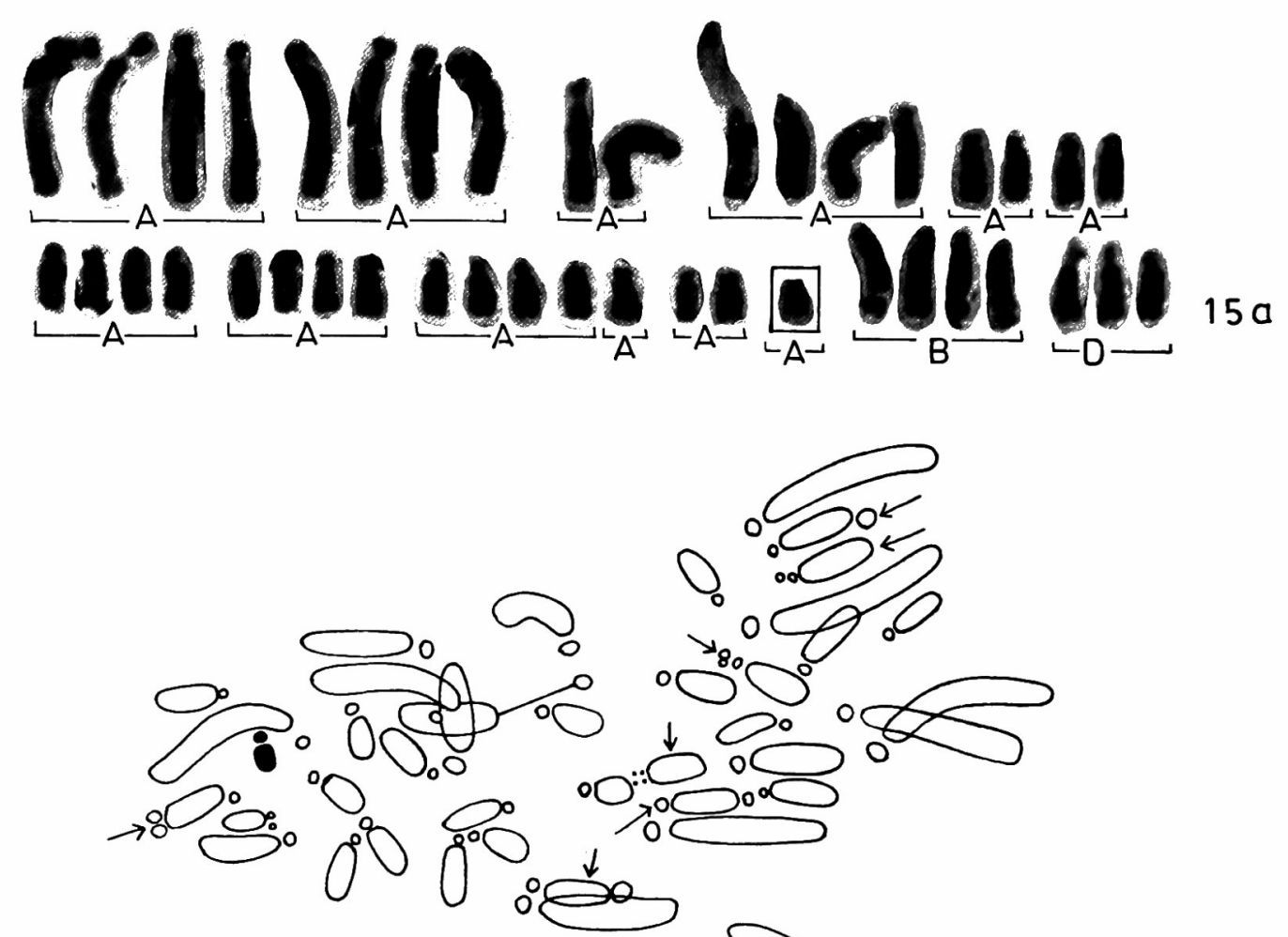

$15 b$


Fig. 15. 15a, idiogram of an aneuploid regenerated plant corresponding to Figs. 15b, c. Extra chromosome is marked. $15 \mathrm{~b}, 15 \mathrm{c}$, somatic metaphase plate showing 41 chromosomes. Extra chromosome is drawn in black. Arrow indicate chromosomes with secondary constrictions.

scored showed diploid chromosome number. These plants did not show vigorous growth.

Karyotype analysis: The karyotype of Urginea indica $2 \mathrm{n}=20$ is highly asymmetical both in size and morphology (Jha and Sen 1983b). The chromosome size ranges form $4 \mu \mathrm{m}$ to $17 \mu \mathrm{m}$ and there is an abrupt size difference. The constrictions are mostly subterminal to extremely 
subterminal in nature (Figs. 2, 2a).

The chromosomes were first distinguished based on morphology as presumptively (i) unaltered (i.e., indistinguishable from chromosomes in the native karyotype) and altered. The karyotype of the diploid plant before callus initiation consisted of 10 pairs of chromosomes. According to length of whole chromsomes as well as relative length of arms, following groupings have been made in the karyotypes (Figs. 1, 2a).

\section{Unaltered chromosome types}

Type A-Chromosomes with subterminal primary constriction. Length varies from 4-17 $\mu \mathrm{m}$. There are 8 pairs of type $A$ chromosome in the parental plant.

Type B-Chromosomes with two constrictions-primary and secondary. One is subterminal and other extremely subterminal in position. Middle arm is longer than the other two arms. There is one pair of type B chromosomes in the parental plant.

Type D-Chromosomes with two constrictions primary and secondary. The two constrictions are very near to each other at the distal end of the longer arm and are of equal size. One pair is present in the diploid source plant.

\section{Altered chromosome types (Fig. 1)}

Five main subcategories of altered chromosome morphology could be distinguished based on centromeric index.

Type $\mathrm{A}^{\prime}$ : Chromosomes with submedian primary constriction. Length $5-7 \mu \mathrm{m}$, unpaired.

Type $\mathbf{C}, \mathbf{C}^{\prime}$ : Chromosomes with two constrictions, primary and secondary. One is subterminal and the other median $(C)$ or submedian $\left(C^{\prime}\right)$.

Type $\mathrm{D}^{\prime} \mathrm{D}^{\prime \prime}$ : Same as $\mathrm{D}$ but the two constrictions at distal end of long arm are unequal. In $D^{\prime}$, the middle segment is shorter than the distal segment. In $D^{\prime \prime}$, the distal one is a satellite.

\section{Tricentrics}

Chromosomes with three constrictions have also been noted in two diploid plants (Fig. $16 \mathrm{~g})$. In each case they occur singly.

\section{Plants showing karyotype stability}

On the basis of morphology of chromosomes, it was found that of the 82 plants analyzed (Table 2), 56\% (41 diploid and 5 tetraploid) showed no alteration in their karyotypes. The karyotype of diploid unaltered plants are $A_{8(2)}+B_{1(2)}+D_{1(2)}$ (Fig. 11a). The tetraploid unaltered types showed duplication of all chromosomes except type $D$ which was repersented by one pair. The karyotype formula of such tetraploids are $A_{8(4)+1(2)}+B_{1(4)}+D_{1(2)}$.

Plants showing karyotype instability (Table 3)

Of the 36 variable karyotypes, 29 were diploid and 7 tetraploid (Tables 2 and 3). Of these 36 plants, 31 plants show variation in both $\mathrm{A}$ and $\mathrm{D}$ chromosomes. The alteration in A chromosome is mainly due to deletions leading to heteromorphicity. However, maximum plants showed variation in D chromosomes (Table 2) leading to structurally altered types $\mathrm{D}^{\prime}$ and $\mathrm{D}^{\prime \prime}$ due to translocation. None of the regenerants showed any variation in B type chromosomes (Table 3). The extra chromosome was smallest and subterminal (Fig. 15a). The most prevalent structurally altered chromosome was $D^{\prime}$ type which occurred in 34 out of 36 variants (Table 2). 

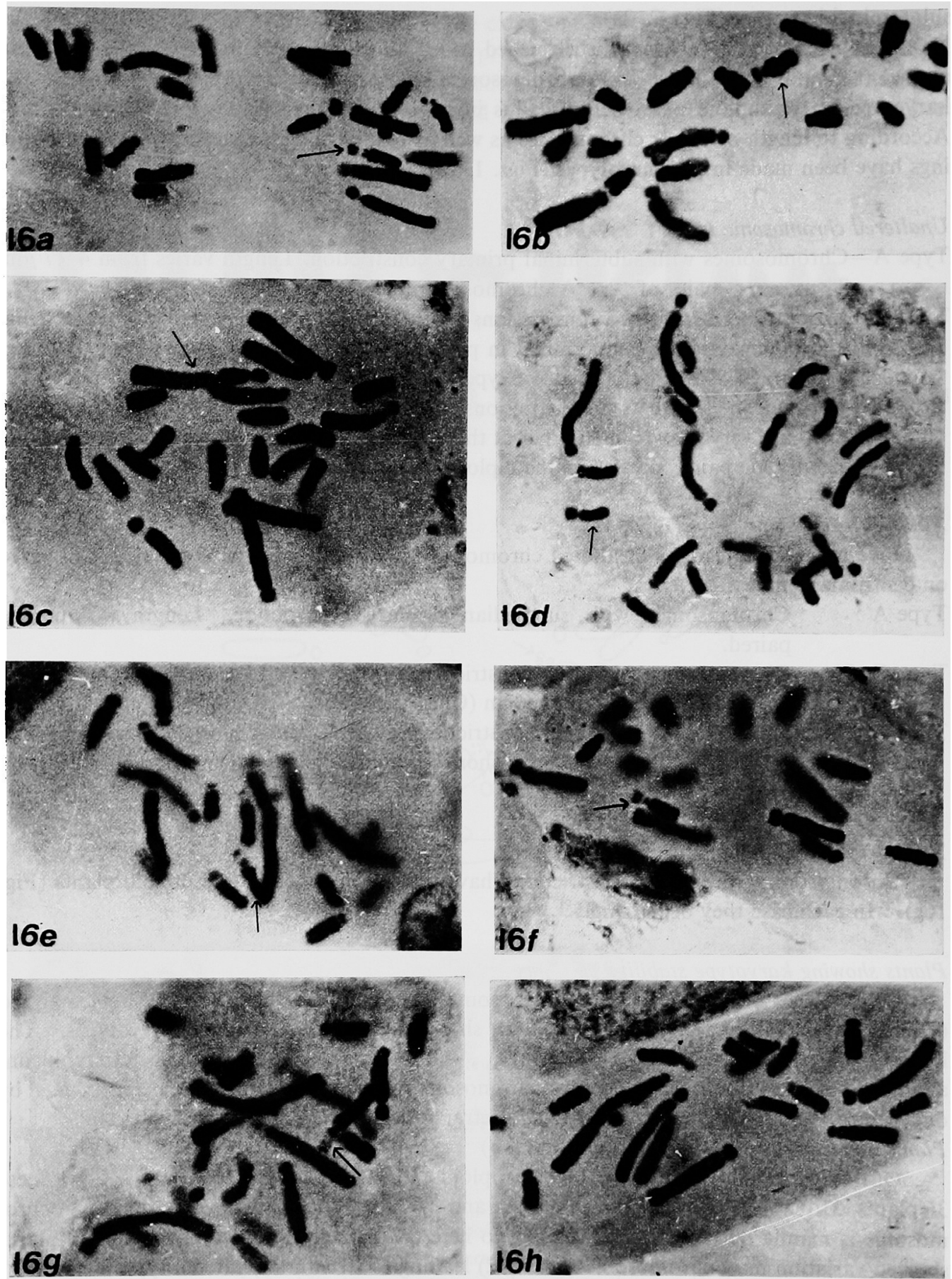

Fig. 16. Somatic metaphase plates from diploid regenerated plants showing alteration in nucleolar and non-nucleolar chromosomes $(\nearrow)$. 


\section{Discussion}

The present investigation on diploid $U$. indica shows that high number of variable plants can be regenerated successfully from callus cultures. This is of special significance since $U$. indica is a medicinal species yielding cardiac glycosides (Jha and Sen, 1981). A detailed investigation of bufadienolides are being carried out to ascertain the usefulness of these cytological variants and particularly the tetraploids as they are derived from a diploid high yielding parental strain (Jha and Sen 1983b). Nuclear cytology of callus induction in $U$. indica (Jha and Sen 1987) has revealed that explant was homogeneous but calli showed high degree of variability right from 8 weeks of initiation. The changes occurring in calli are transmitted to regenerated plants and progeny, as noted in other species (Bayliss 1980, Larkin and Scowcroft 1981, Sree Ramlulu et al. 1983, Lorz and Scowcroft 1983) as well.

Some of the secondary constrictions observed in karyotypes of regenerated plants could not be recorded in root tips of the parental plant. Most of the altered types observed are the results of translocations. Since specific parts translocated could not be identified, decision as to whether cells actually lost or gained chromosome segments could not be made. The type $\mathrm{D}$ chromosome was found only in one pair in all naturally occurring chromosomal races of $U$. indica at all ploidy level (Jha and Sen $1983 \mathrm{c}$, b). However, in regenerated tetraploids with one extra chromosome, this type D was noted in a group of 3 chromosomes. Though these are presumably autoployploids, but the chromosomes were not noted in groups of 4 , indicating the role of structural alterations causing the variablility. Different types of chromosomal variants could thus be created through in vitro growth.

The regenerants comprises of diploid, tetraploid, aneuploid and mosaics. Of the numerical variants, diploids occur in maximum frequency indicating its selective value.

The chromosome behaviour in root tip cells gradually became stable. The retention of stable karyotype in tetraploids was noted after several cell cycles. It may, however, be noted that the stability of aneuploids is rather meagre as compared to diploids and tetraploids. It is a clear index of the fact that the balanced chromosome constitution is preferentially selected in regeneration after in vitro growth. No pronounced phenotypic or physiological changes could be attributed to the regenerants so far. It is likely that such alterations might not have affected the external morphological characters to an appreciable extent. A detailed anatomical, physiological and biochemical analysis may reveal the effects of the genotypic differences on metabolism of regenerants.

\section{Summary}

Plants regenerated from callus cultures of diploid Urginea indica Kunth., Indian squill, showed variability in both chromosome number and morphology. In addition to diploids, regenerants included tetraploid, aneuploid and mosaic plants. Structurally altered chromosomes were detected in diploids as well as tetraploids. Structural alterations involved mainly the nucleolar chromosomes.

Acknowledgements

SJ is indebted to University Grants Commission for financial assistance and to Prof. A. K. Sharma, Programme Coordinator, Centre of Advanced Study, for facilities and encouragement.

\section{References}

Ancora, G. and Sree Ramlulu, K. 1981. Plant regeneration from in vitro cultures of stem internodes in self incompatible triploid Lycopersicon peruvianum Mill. and cytogenetic analysis of regenerated plants. 
Plant Sci. Lett. 22: 197-204.

Bennici, A. and D'Amato, F. 1978. In vitro regeneration of durum wheat plants I. chromosome number of regenerated plantlets. Z. Pflanzenzucht. 81: 305-311.

Browers, M. A. and Orton, T. J. 1982. Transmission of gross chromosomal variability from suspension cultures into regenerated plants. J. Hered. $73: 159-162$.

Bayliss, M. W. 1980. Chromosomal variation in plant tissue culture. In: International Review of Cytology. Suppl. 11A. Perspectives in Plant Cell and Tissue Culture. (I. K. Vasil ed.), pp. 113-134. Academic Press, New York.

Cummings, D. P., Green, C. E. and Stuthman, D. D. 1976. Callus induction and plant regeneration in oats. Crop Sci. 16: $465-470$.

Flick, C. E., Evans, D. A. and Sharp, W. R. 1983. Organogenesis. In Handbook of Plant Cell Culture. 1: 13-81.

Green, C. E., Phillips, R. L. and Wang, R. S. 1977. Cytogenetic analysis of plants regenerated from maize tissue cultures. Maize Genet. Newslett. 51: 53-54.

Jha S. and Sen S. 1981. Bufadienolides in different chromosomal races of Indian squill. Phytochemistry 20: 524-526.

- and - 1983a. A quantitation of principal bufadienolides in different cytotypes of Urginea indica. Planta Medica 47: 43-45.

- and - 1983b. Chromosome study of diploid Indian squill. Cytologia 48: 79-86.

- and - 1983c. Chromosome study of polyploid Indian squill. Cytologia 48: 407-418.

- and - 1987. Nuclear changes and organogenesis during callus culture of Urginea indica Kunth. Cytologia 52: 95-100.

- and Mitra, G. C. and Sen, S. 1984. In vitro regeneration from bulb explants of Indian squill-Urginea indica Kunth. Plant Cell Tissue and Organ Culture 3: 91-100.

Krikorian, A. D., Staicu, S. A. and Kann, R. P. 1981. Karyotype analysis of a day lily clone reared from aseptically cultured tissues. Ann. Bot. 47: 121-131.

Larkin, P. J. and Scowcroft, W. R. 1981. Somaclonal variation-a novel source of variability from cell cultures for plant improvement. Theor. Appl. Genet. 60: 197-214.

Lorz, H. and Scowcroft, W. R. 1983. Variability among plants and their progeny regenerated from protoplasts of Su/So heterozygotes of Nicotiana tabacum. Theor. Appl. Genet. 66: 67-75.

McCoy, T. J. and Bingham, E. T. 1977. Regeneration of diploid alfa alfa plants from cells grown in suspension culture, Plant Sci. Lett. 10: 59-66.

-, Phillips, R. L. and Rines, H. W. 1982, Cytogenetic analysis of plants regenerated from Oat (Avena sativa) tissue cultures: high frequency of partial chromosome loss. Can. J. Genet. Cytol. 24: 37-50.

Newell, C. A., Rhoads, M. L. and Bidney, D. L. 1984. Cytogenetic analysis of plants regenerated from tissue explants and mesophyll protoplasts of winter rape, Brassica napus L. Can. J. Genet. Cytol. 26: 752761.

Novak, F. J. 1980. Phenotype and cytological status of plants regenerated from callus cultures of Allium sativum L. Z. Pflanzenzuchtg. 84: 250-260.

Orton, T. J. 1980. Chromosomal variability in tissue cultures and regenerated plants of Hordeum. Theor. Appl. Genet. 56: 101-112.

Reisch, B. 1983. Genetic variability in regenerated plants. In Handbook of Plant Cell Cultures. (Evans, D. A., Sharp, W. R., Ammirato, P. V. and Yamada, Y. eds.) Vol. I: 13-81.

Sheridan, W. F. 1975. Plant regeneration and chromosome stability in tissue cultures, In Genetic Manipulations with Plant Material (L. Ledoux ed.), pp. 263-293. Plenum Press, New York.

Sree Ramlulu, K., Dijkhuis, P. and Roest, S. 1983. Phenotypic variability and ploidy level of plants regenerated from protoplasts of tetraploid potato (Solanum tuderosum L. cv. 'Bintje'), Theor. Appl. Genet. 65: 329-339. 